\title{
EXPERIMENTOTECA DE MATEMÁTICA: discussões sobre possibilidades de sua utilização no processo de ensino e aprendizagem de Matemática
}

\author{
EXPERIMENTATION LIBRARY FOR MATHEMATICS: \\ discussions about its use in the process of \\ teaching and learning Mathematics
}

\author{
Renata Cristina Geromel Meneghetti*
}

\begin{abstract}
Resumo
O presente trabalho discute algumas possibilidades de utilização da Experimentoteca de Matemática (equivalente a um Laboratório de Matemática) no processo de ensino e aprendizagem dessa ciência. Defende-se que no processo de elaboração do conhecimento, os experimentos matemáticos, desde que trabalhados adequadamente, podem auxiliar na criação de significados dos objetos matemáticos neles contemplados. Nessa direção, focaliza-se um dos experimentos e suas atividades com o objetivo de indicar as possibilidades de relacioná-las com abordagens alternativas do ensino de Matemática, tais como a Resolução de problemas e a Modelagem Matemática. $\mathrm{O}$ artigo defende a Experimentoteca como uma possível aliada no desenvolvimento de trabalhos alternativos no ensino dessa disciplina.
\end{abstract}

Palavras-chave: Experimentoteca de Matemática. Ensino e Aprendizagem de Matemática. Abordagens Alternativas. Educação Básica.

\begin{abstract}
This article discusses possible uses of the Experimentation Library for Mathematic (similar to a Mathematics Laboratory) in the process of teaching and learning Mathematics. It is argued that in the process of knowledge development, as long as mathematical experiments are properly done, can help in the creation of meanings of mathematical objects. Taking this into consideration, the article focuses in one of the experiments and its activities trying to indicate the possibilities of relating it to alternative approaches for the teaching of mathematics, such as Resolution of Problems and Mathematical Modeling. The article defends Experimentation Library as a possibility for the development of alternative forms in the teaching of Mathematics.
\end{abstract}

Keywords: Experimentation Library for Mathematics. Teaching and Learning of Mathematics. Alternative Approaches. Basic Education.

\section{Introdução}

O termo "Experimentoteca" tem sido compreendido como um laboratório de Ciências da Natureza, constituindo-se de materiais experimentais disponíveis para a utilização do professor em sala de aula.

Segundo Tomazello e Schiel (1998, p. 6), "Experimentoteca é um laboratório das Ciências da Natureza que pretende racionalizar o uso de material experimental, da mesma maneira que uma biblioteca pública facilita o acesso de um grande número de publicações a um público extenso". Compreende-se que o termo "racionalizar" posto por esses autores denota o significado de subsidiar o trabalho do professor com o uso de materiais experimentais em sala de aula. A ideia principal das Experimentotecas é funcionar como uma fonte de materiais para que o professor possa realizar experimentos a fim de enriquecer suas aulas. A criação de uma Experimentoteca foi delineada, em princípio, para o ensino de Física, Química e Biologia. Uma primeira versão foi projetada para o Ensino Fundamental da Educação Básica.

Essa Experimentoteca compõe-se de kits que proporcionam ao aluno a oportunidade de realização de práticas experimentais em sala de aula (constituindo-se como recurso pedagógico auxiliar

\footnotetext{
* Professora doutora do Instituto de Ciências Matemáticas e de Computação da Universidade de São Paulo. E-mail: rcgm@icmc.usp.br
} 
na formação e compreensão de conceitos), e tem sido adotada por Centros de Ciências, Prefeituras Municipais, Institutos Universitários (vinculados à Educação Básica), Parques de Tecnologia ou Clubes de Ciência. Um mesmo acervo atende simultaneamente de 20 a 30 escolas e mais de 4 mil alunos por ano podem usá-lo. ${ }^{1}$

Nesse contexto, numa segunda etapa de implementação do projeto Experimentoteca, deu-se a criação de uma Experimentoteca de Matemática. Essa é composta de diversas atividades didáticas para o Ensino de Matemática (níveis Fundamental e Médio). Tais atividades foram desenvolvidas, na maioria das vezes, utilizando-se de materiais experimentais ou jogos pedagógicos, visando proporcionar a construção dos conceitos matemáticos envolvidos.

Neste artigo relato, segundo minha compreensão, a constituição desta "Experimentoteca de Matemática" com o propósito de refletir sobre sua utilização no processo de ensino e aprendizagem da disciplina. Portanto, essa pesquisa foca o seguinte questionamento: que possibilidades de trabalhos em sala de aula de Matemática poderiam se dar por meio da utilização de uma Experimentoteca de Matemática?

Compreendo que uma Experimentoteca, uma vez que é constituída de experimentos, remete-nos ao empirismo, corrente filosófica que busca alicerçar o conhecimento na experiência. $O$ empirista inglês Locke, por exemplo, concebeu que todas nossas ideias são derivadas ou da sensação (experiência exterior) ou da reflexão (experiência interior). (LOCKE, 1980).

Entretanto, assumo aqui a postura, defendida em Meneghetti e Bicudo (2003); Meneghetti (2009), de que deve haver um equilíbrio entre o intuitivo (incluindo o experimental) e o lógico no processo de constituição do conhecimento matemático. O intuitivo, no caso, inclui o experimental, pois é compreendido como um conhecimento de apreensão imediata, podendo ou não ter origem na experiência. $O$ lógico é considerado como uma linguagem formal por meio da qual sistematizamos/formalizamos o conhecimento. Essa postura aplicada à ideia da Experimentoteca implica em compreender que os experimentos, neste caso, deverão ser seguidos de discussões para que ocorra uma sistematização dos conceitos matemáticos envolvidos.

Os experimentos, enquanto materiais didáticos disponíveis aos professores são aqui compreendidos, tal como posto por Lorenzato (2006), como possíveis facilitadores da aprendizagem, meios de auxiliar o ensino. Contudo, como salienta esse últi-

\footnotetext{
1 Informação disponível no site: <http://www.cdcc.usp.br/exper/ fundamental>
}

mo autor, para que haja aprendizagem é ainda necessária uma atividade mental por parte do aluno, o que também é reforçado em Passos (2006, p. 81):

[...] os conceitos matemáticos que eles [alunos] devem construir, com a ajuda do professor, não estão em nenhum dos materiais de forma que possam ser abstraídos deles empiricamente. Os conceitos serão formados pela ação interiorizada do aluno, pelo significado que dão às suas ações, às formulações que enunciam, às verificações que realizam.

Por tais motivos, é necessário que o professor, a partir de experimentos ou outros materiais didáticos, promova uma discussão com seus alunos sobre os conceitos matemáticos focalizados, auxiliando-os no estabelecimento de relações com outros conceitos, na produção de significados e na sistematização do conteúdo. Ou seja, compreendem-se os experimentos como um meio a partir do qual se pode promover a aprendizagem dos conceitos abordados.

\section{A origem da Experimentoteca de Mate- mática}

A criação da Experimentoteca de Matemática ocorreu vinculada a um projeto mais amplo ("Instrumentação para o Ensino das Ciências e da Natureza e da Matemática") do Centro de Divulgação Científica e Cultural da Universidade de São Paulo - São Carlos/SP/Brasil (CDCC). Esse projeto tinha como finalidades principais: desenvolver, produzir e divulgar materiais didáticos adequados às novas diretrizes curriculares para o Ensino Médio das Ciências da Natureza, Matemática e suas tecnologias; a fim de colaborar com a formação inicial e continuada de professores de Biologia, Física, Química e Matemática, bem como ampliar o acervo do CDCC. ${ }^{2}$ Tal projeto foi desenvolvido junto ao CDCC, em parceria entre a Universidade Federal de São Carlos (UFSCar) e a Universidade de São Paulo - Campus de São Carlos (USP-São Carlos), com apoio do ConseIho Nacional de Desenvolvimento Científico e Tecnológico (CNPq), da Financiadora de Estudos e Projetos (FINEP) e da Vitae Apoio à Cultura, Educação e Promoção Social (VITAE).

A equipe geral, da qual a autora deste artigo fazia parte, foi formada por pesquisadores das áreas de Educação, Química, Física, Biologia e Matemática, professores do Ensino Médio da rede pública, técnicos de laboratórios, alunos dos cursos de Licenciatura da USP e UFSCar e de programas de pós-graduação dessas universidades. Essa composição diversificada permitiu a construção de diálogos transdisciplinares em diferentes níveis,

\footnotetext{
${ }^{2}$ Vale lembrar que a Matemática não fazia parte do acervo inicial, o qual contemplava experimentos para o Ensino Fundamental nas áreas de Física, Química e Biologia.
} 
possibilitando não somente que os produtos obtidos tivessem uma dimensão da visão interdisciplinar do conhecimento, como também que todos os seus membros apresentassem ganhos de conhecimentos tanto em sua especialidade quanto na integração com outras áreas. ${ }^{3}$

Numa perspectiva interdisciplinar, a equipe geral buscou reunir-se em torno de temas que pudessem ser trabalhados em diferentes áreas do conhecimento, com o objetivo comum de contribuir com o processo ensino e aprendizagem da escola pública. O projeto foi fundamentado em alguns pontos, tais como: a maioria das escolas públicas não possui materiais didáticos recentes para o ensino de Ciências e Matemática e, quando possuem, são obsoletos ou subutilizados; os materiais existentes no mercado nem sempre promovem a contextualização do conhecimento; materiais didáticos inovadores muitas vezes não vêm acompanhados de uma proposta de formação de educadores, o que dificilmente muda a prática pedagógica dos professores; o ensino, baseado em desafios e na Resolução de Problemas, é fortalecido com o uso de materiais didáticos e kits pedagógicos bem elaborados; a interdisciplinaridade, bastante enfatizada pelos Parâmetros Curriculares Nacionais - PCN (BRASIL, 1997; 1999), é difícil de ser incorporada à prática pedagógica dos professores.

Nesse contexto, formaram-se subgrupos de trabalho por área; dentre esses se originou um grupo de discussão sobre o ensino de Matemática, marcando a constituição a Experimentoteca de Matemática, foco de discussão deste artigo.

\section{Aspectos metodológicos que embasaram a construção dos materiais que compõem a Experimentoteca de Matemática}

O grupo de discussão sobre o ensino de Matemática, em seu momento inicial (primeiro ano), foi constituído por dois professores universitários (como coordenadores, um matemático e a autora deste artigo enquanto educadora Matemática), além de professores do Ensino Fundamental e alunos dos cursos de Licenciatura em Matemática de duas universidades públicas envolvidas. Naquele ano foram elaborados os experimentos de Matemática para o Ensino Fundamental. No segundo ano, no qual foram construídos os experimentos para o Ensino Médio, outros professores da Educação Básica participaram do grupo; no caso, esses professores estavam vinculados ao Ensino Médio. O terceiro ano foi a fase de experimentação e aperfeiçoamento dos materiais, que ficaram disponíveis para empréstimo

\footnotetext{
${ }^{3}$ Reuniões frequentes permitiram o acompanhamento do trabalho de cada subequipe (grupos de trabalhos específicos).
}

aos professores de Matemática da Educação Básica, a fim de que os utilizassem em suas aulas, acompanhado de um questionário de avaliação para que sugestões fossem apresentadas. Esse procedimento possibilitou um novo aprimoramento dos materiais da Experimentoteca de Matemática. No último ano mencionado, o grupo já não existia, de forma que a autora deste trabalho, como coordenadora das atividades de Matemática do CDCC, ficou responsável por acompanhar essa fase de experimentação e aperfeiçoamento do material da Experimentoteca da Matemática. Após essa fase de aprimoramento do material, o CDCC deu início à disseminação da Experimentoteca para outros polos de divulgação.

Essas foram as etapas que levaram à constituição e aprimoramento da Experimentoteca de Matemática. O experimento focado neste trabalho faz parte desse acervo, o conjunto das atividades que o compõe pode ser trabalhado com alunos desde o Ensino Fundamental (a partir da $7^{\mathrm{a}}$ série) até o Ensino Médio ( $3^{\circ}$ ano). A seguir, comenta-se com mais detalhes a dinâmica de trabalho no processo de elaboração das atividades que compuseram a Experimentoteca de Matemática.

No processo de elaboração desta Experimentoteca buscamos desenvolver atividades que, na maioria das vezes, utilizam-se de materiais experimentais e/ou jogos, com o intuito de levar o aluno a construir os conceitos subjacentes a essas atividades. Os jogos, no caso, são jogos pedagógicos, ou seja, possuem um caráter educativo e lúdico. (MOURA, 1994).

O passo inicial desse trabalho consistiu no levantamento, junto aos professores da Educação Básica (integrantes do grupo), de temas que apresentavam maiores dificuldades de ensino. Mediante diversas discussões, decidiu-se iniciar a elaboração de materiais didáticos compreendendo os tópicos: números inteiros, números racionais e Geometria I e II (para o Ensino Fundamental). Posteriormente, também foram abordados os tópicos de equações e inequações do primeiro grau. Para o Ensino Médio, foram desenvolvidos materiais focando os seguintes conteúdos: funções, análise combinatória, probabilidade, sistemas lineares e matrizes.

Inicialmente, foram elaboradas diversas atividades para o desenvolvimento de cada um desses tópicos. Aplicações pilotos foram sendo efetuadas pelos professores participantes e por alunos do curso de Licenciatura em Matemática nos estágios supervisionados de disciplinas de Prática de Ensino ministradas pela autora deste trabalho. Após essa etapa e devido à inviabilidade de se reproduzir tudo, algumas dessas atividades foram escolhidas para compor a Experimentoteca de Matemática. Para tal escolha, foi levado em consideração as atividades que haviam sido bem sucedidas nas aplicações pi- 
loto quanto aos seguintes aspectos: clareza da proposta; possibilidade de os alunos construírem os conceitos envolvidos; e se as atividades eram interessantes (no sentido de favorecer a motivação e o envolvimento dos alunos).

Vale destacar que foi muito importante, na fase de elaboração dos materiais, a participação e o envolvimento de professores da Educação Básica, o que proporcionou ao grupo um vínculo maior com questões referentes ao ensino e aprendizagem de Matemática em sala de aula. Além disso, ao se considerar as vivências desses professores com o processo de ensino e aprendizagem da disciplina, foi possível uma maior adequação dos materiais referente aos pontos que esses professores relatavam suscitar maiores dificuldades entre os alunos. Isso pode também ser observado no depoimento de uma das professoras:

[...] Tendo sempre em mente as dificuldades encontradas por nós professores, principalmente os da rede estadual, em sala de aula, os kits até então propostos são em geral simples para serem aplicados, e contemplam as maiores dificuldades dos alunos, sejam eles do Ensino Fundamental ou Médio. $\left(\right.$ Professora $\left.L_{1}\right){ }^{4}$

Ademais, ao participarem do projeto e se questionarem sobre as dificuldades de seus alunos, os professores foram também levados a refletir sobre suas práticas em sala de aula ou repensá-las, como apontado no seguinte relato: "Enquanto professora, a minha participação na elaboração dos materiais pedagógicos, me proporcionou crescimento profissional e uma reflexão sobre a minha prática [...] pude inovar e trocar experiências com outros profissionais." (Professora $\mathrm{L}_{2}$ ). ${ }^{5}$

Observa-se que esse ponto de refletir sobre a prática é muito destacado em referências de educadores preocupados com a formação do professor. Para Gómez (1992), a reflexão implica a imersão consciente do homem no mundo de sua experiência, um mundo carregado de conotações, valores, intercâmbios simbólicos, correspondências afetivas, interesses sociais e cenários políticos: "O profissional competente actua refletindo sobre a acção, criando uma nova realidade, experimentando, corrigindo e inventando através do diálogo que estabelece com essa mesma realidade [...]" (GOMÉZ, 1992, p. 110).

$\mathrm{Na}$ Educação Matemática, Oliveira e Ponte (1997, p. 13), em um levantamento que realizaram sobre o professor de Matemática, suas concepções, saberes e desenvolvimento profissional, destacam

\footnotetext{
${ }^{4} \mathrm{~A}$ professora $L_{1}$ leciona em uma escola do Ensino Médio da rede pública e também no Ensino Fundamental de uma escola particular.

${ }^{5} \mathrm{~A}$ professora $\mathrm{L}_{2}$ atua no ensino público, nos níveis Fundamental e Médio.
}

que: "[...] a maior fraqueza da investigação até o presente momento tem sido a dificuldade (e, por vezes, o desinteresse) em estudar o conhecimento na sua relação com a prática profissional." Esses autores ainda alertam: "[...] o estudo do conhecimento profissional do professor não pode progredir muito se não tiver como referência sua prática e as condições em que esta se desenvolve."

Assim, a integração unversidade-escola apresenta-se como fundamental para o desenvolvimento da Educação, em especial quando se trabalha com desenvolvimento de materiais didáticos para o ensino e a aprendizagem de Matemática. Portanto, entende-se que foi muito valiosa e importante essa interação com professores da Educação Básica no processo de constituição da Experimentoteca de Matemática.

\section{A composição da Experimentoteca}

Atualmente, a Experimentoteca completa do CDCC é constituída por 98 kits, sendo 61 do Ensino Fundamental e 37 do Ensino Médio. Contém basicamente materiais experimentais, além de vídeos, mapas, modelos e jogos, os quais possibilitam a experimentação por parte dos alunos, havendo material para 10 equipes de alunos trabalharem simultaneamente sobre cada tema. Contempla as áreas de Física, Química, Biologia e Matemática.

A parte de Matemática, que denominamos de Experimentoteca de Matemática, é constituída por 22 kits experimentais, sendo 14 referentes a conteúdos do Ensino Fundamental e oito relacionados a conteúdos do Ensino Médio, de acordo com o Quadro 1: 
Quadro 1 - Kits experimentais da Experimentoteca de Matemática

\begin{tabular}{l}
\hline ENSINO FUNDAMENTAL \\
\hline Operações com Números Inteiros \\
\hline Jogo do Dinossauro \\
\hline Bingo das Retas Fracionárias \\
\hline Representação das Frações (estojo das frações) \\
\hline Jogo da Trilha Geométrica \\
\hline Construindo Tangram com Dobraduras \\
\hline Um Pastor Esperto \\
\hline Atividades sobre Ângulos \\
\hline Mico dos Poliedros \\
\hline Estimando Alturas \\
\hline Pontos Notáveis \\
\hline Representação do Teorema de Pitágoras \\
\hline Uma Balança para Introduzir Equações do $1^{\circ} \mathrm{Grau}$ \\
\hline Uma Balança para Introduzir Inequações do $1^{\circ} \mathrm{Grau}$ \\
Fonte: A autora.
\end{tabular}

Para cada um desses kits experimentais há um roteiro para os alunos e um roteiro para o professor. Em ambos constam: o título, uma introdução, uma ou mais questões prévias, o objetivo do experimento, os materiais e procedimentos necessários para o desenvolvimento do experimento e questões de reflexões para o desenvolvimento das atividades ou fechamento das mesmas. No roteiro do professor há também discussões complementares e sugestões para o desenvolvimento de outras atividades correlatas.

Atualmente, esse material está disponível no CDCC para empréstimo aos professores da rede pública e particular do município de São Carlos e região. Um trabalho de disseminação desse material para outros centros de Ciências em todo território nacional tem sido efetuado pelo CDCC. A seguir, um dos experimentos de Matemática será focalizado a fim de discutir algumas possibilidades metodológicas para sua utilização em sala de aula.

\section{Um exemplo de kit experimental de Mate- mática: "Estudo da Poluição numa Aula de Matemática"}

Como exemplo dos kits pedagógicos desenvolvidos para o ensino e aprendizagem de Matemática, neste artigo focalizo um constituído de diversas atividades experimentais, que relacionam Matemática e meio ambiente ao abordar o tema "a poluição de lagos".

Esse assunto foi primeiro mencionado por Sandefur (1992); ocasião na qual o autor se concentra na ingestão de drogas pelo organismo e, ao final, sugere que o problema das drogas pode ser retrabalhado em termos de poluição. Uma primeira aplicação dessas ideias foi introduzida a professores que atuavam junto ao Ensino Médio no "Projeto

\begin{tabular}{|l|}
\hline ENSINO MÉDIO \\
\hline Estudo da Poluição numa Aula de Matemática \\
\hline O Jogo dos Discos \\
\hline A Tábua da Fortuna \\
\hline Genética e Combinatória \\
\hline Jogando e Ganhando \\
\hline Sinal de uma Permutação \\
\hline Futebol e os Cartolas \\
\hline Permutações, Arranjos e Combinações \\
\hline \\
\hline \\
\hline \\
\hline
\end{tabular}

Integrado de Ciências e Matemática para Professores de Rede Pública de Ensino de São Carlos" da UFSCar. (SALVADOR et al., 2003). Essa versão preliminar foi apresentada ao grupo de discussão sobre o ensino de Matemática com o propósito de compor uma das atividades da Experimentoteca do Ensino Médio. Correções e adaptações foram sendo realizadas a partir de discussões com todos os integrantes do grupo, no sentido de aperfeiçoar aspectos metodológicos das atividades, tais como a forma de propor e analisar a situação, levantamento de questões importantes para o desencadeamento e fechamento das atividades e também para promover reflexões sobre o tema.

Assim, esse grupo preocupou-se com a forma de apresentar e explorar as atividades, a proposta do desenvolvimento do kit experimental, de forma que o aluno pudesse manipular o material, fazer uma simulação da situação por meio de experimento e, a partir disso, o conteúdo ser trabalhado. Por fim, foram desenvolvidos os roteiros do professor e do aluno para acompanhar e orientar o experimento.

Um dos principais objetivos desse kit é desenvolver aulas a partir de experimentos que simulam o processo de poluição e o processo natural de recuperação de um lago. O início das atividades se dá com a simulação de um problema real sobre poluição no Meio Ambiente.

O conjunto de atividades que compõe o kit experimental proposto para esse tema pode ser trabalhado com alunos desde o Ensino Fundamental (a partir da $7^{\text {a }}$ série) até o Ensino Médio ( $3^{\circ}$ ano), visto que o problema inicial pode ser retomado em níveis cada vez mais elaborados e aprofundados, configurando uma nova situação-problema.

O material é constituído de quatro fichas de atividades, com a realização de um experimento na fase inicial e outro na fase final (ocasião em que a si- 
tuação-problema inicial sofre variações que exigem a realização de um novo experimento).

A título de ilustração, será apresentada na íntegra a primeira ficha de atividades (versão do aluno) e as demais serão comentadas resumidamente. Na sequência, tomo esse experimento para discutir sobre algumas possibilidades didático-pedagógicas referentes à sua utilização no processo de ensino e aprendizagem de Matemática.

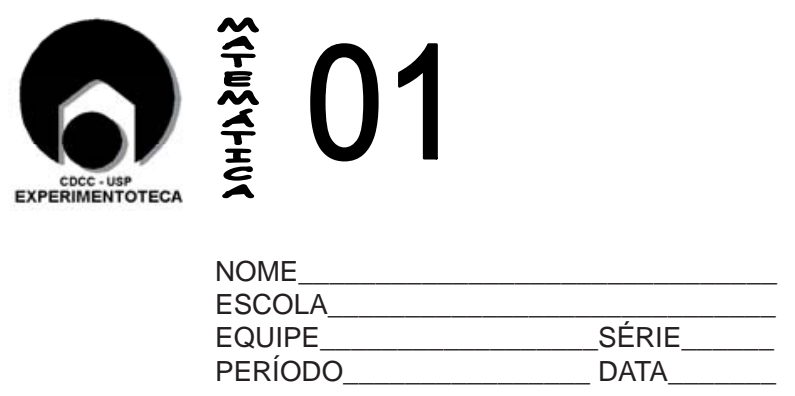

\section{Estudo da Poluiçãa numa Aula de Matemáitica}

\section{Roteiro do aluno}

Objetivo: Esta atividade tem múltiplos objetivos: evidenciar a importância do ferramental matemático no estudo e resolução de problemas que ocorrem ou naturalmente, ou como consequência da intervenção do homem na natureza, desenvolvimento da cidadania, incentivar a reflexão e desenvolver o espírito crítico do aluno no que diz respeito a essa intervenção.

\section{Material:}

- 3 vasilhames transparentes

- 1 copo plástico

- 1 frasco com corante

Observação: O primeiro vasilhame deverá ser utilizado para armazenar a água limpa, a qual será utilizada para repor a água do "lago" em cada etapa de sua despoluição; o segundo vasilhame deverá representar o "lago" e o terceiro deverá ser utilizado para armazenar a água removida do "lago".

Procedimento: Este kit deve ser utilizado com a supervisão do professor, que deverá orientar as atividades a serem desenvolvidas em cada etapa. Sugere-se que a classe seja dividida em pequenos grupos.

\section{ATIVIDADE 1}

"Suponha que em um habitat constituído por um lago de águas límpidas, com vegetação e espécimes característicos, seja despejada certa quantidade de um produto poluente e que ocorra um processo de despoluição natural, promovido pelos seres vivos pertencentes a esse habitat. Em uma descrição simplificada desse processo natural de despoluição, suponha que os seres vivos do lago purifiquem $1 / 4$ do volume de água do lago durante qualquer período de 24 horas."

Use um vasilhame transparente para representar o lago e adicione quatro copos de água ao vasilhame para simular a água do lago. Represente o produto poluente por $16 \mathrm{~mL}$ de corante, ou seja, utilize o conta-gotas para adicionar 16 gotas de corante ao vasilhame (cada gota corresponde a $1 \mathrm{~mL}$ ). Veja a Figura 1.

\section{Figura 1}

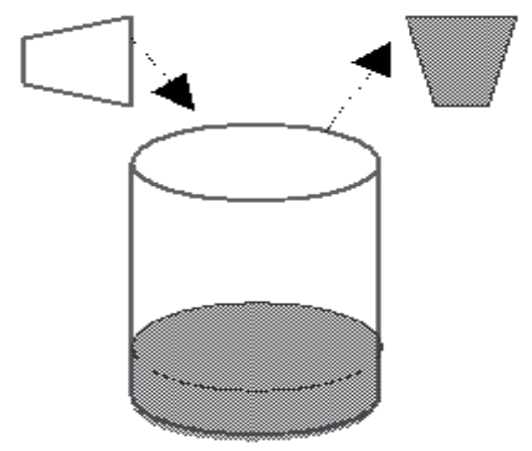

Podemos simular o processo natural de despoluição do lago removendo um copo de água colorida do frasco e recolocando um copo de água pura, como na Figura 2 a seguir.

Figura 2

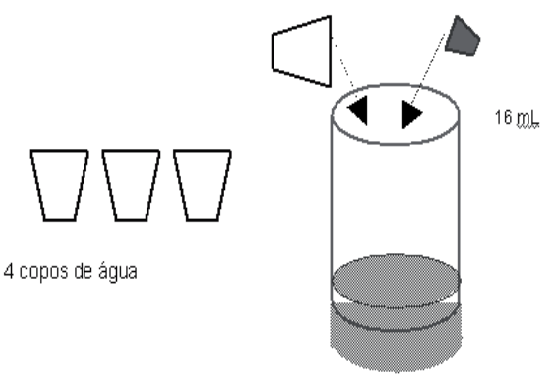

\section{Questões:}

1. Quanto de poluição permanece no vasilhame?

2. Assuma que mais nenhum poluente seja adicionado ao lago. Quanto de poluição é eliminado do lago após as próximas 24 horas?

3. Represente este processo removendo um copo de água colorida e acrescentando um copo de água limpa.

Suponha que $n$ represente o n-ésimo período de 24 horas considerado e que a(n) represente a quantidade de poluente ao final do n-ésimo período de 24 horas.

Continue o experimento para $1,2,3,4 \ldots$ períodos de tempo e descreva o que você observou 
em cada um dos passos efetuados, registrando a quantidade de poluente restante (em $\mathrm{mL}$ ) após cada período. (Use o verso da folha).

Com os resultados obtidos, complete a tabela abaixo. Utilize uma calculadora para acompanhar os cálculos que serão realizados.

\begin{tabular}{|c|c|c|}
\hline \multicolumn{2}{|c|}{ Período de 24 horas $(\mathrm{n})$} & Poluente $(\mathrm{mL}) \mathrm{a}(\mathrm{n})$ \\
\hline $0-24$ & $\mathrm{n}=1$ & 16 \\
\hline $24-48$ & $\mathrm{n}=2$ & \\
\hline $48-72$ & $\mathrm{n}=3$ & \\
\hline $72-96$ & $\mathrm{n}=4$ & \\
\hline $96-120$ & $\mathrm{n}=5$ & \\
\hline $120-144$ & $\mathrm{n}=6$ & \\
\hline $144-168$ & $\mathrm{n}=7$ & \\
\hline
\end{tabular}

4. Supondo que o volume total de líquido no lago (água + poluente) seja 100mL, determine qual fração desse volume representa a quantidade de poluente em cada período de tempo da tabela acima.

5. Pesquisar quais são as substâncias necessárias para fazer um detergente.

6. Quais são as consequências de uma quantidade elevada de detergente num lago com peixes? Explique.

\section{Comentários sobre a continuidade do expe- rimento}

Essa é a primeira ficha de atividade do experimento correspondente à situação-problema: "Suponha que em um habitat constituído por um lago de águas límpidas, com vegetação e espécimes característicos, seja despejada certa quantidade de um produto poluente e que ocorra um processo de despoluição natural, promovido pelos seres vivos pertencentes a esse habitat. Em uma descrição simplificada desse processo natural de despoluição, suponha que os seres vivos do lago purifiquem $1 / 4$ do volume de água do lago durante qualquer período de 24 horas."

Os conteúdos abordados nessa fase do experimento envolvem operações numéricas e introdução aos conceitos algébricos.

Na sequência, ainda referente a essa situação problema, é proposta uma segunda ficha de atividades. Essa é dividida em três partes (A, B e C) e tem por objetivo apresentar as abordagens recursiva, algébrica e gráfica para a situação apresentada.

$\mathrm{Na}$ resolução da segunda ficha de atividade aparecem também os conceitos de progressão geométrica e função logarítmica; além disso, a situação, nesse momento, é trabalhada apenas na forma literal.
Em seguida, o problema é aprofundado ao considerarmos uma nova situação (ficha de atividade 3), a saber: "Considere agora que a cada período de 24 horas uma nova quantidade (fixa) de poluente é adicionada ao lago e que ocorra, também a cada período de 24 horas, um processo de despoluição natural de $1 / 4$ do volume de água."

Um novo experimento é realizado, novas questões são colocadas e outros conceitos são trabalhados. O problema pode ainda ser mais aprofundado acrescentando-se a seguinte situação (ficha de atividade 4): "Para estudar a relação entre o lago e um reservatório de tratamento de água, parte da água poluída do lago será encaminhada para tratamento no reservatório e logo após retornará ao lago. Além disso, uma nova taxa de poluição será acrescida."

Novamente realiza-se o experimento e outras questões são colocadas. Nessa fase são abordados os conceitos de sistemas lineares e matrizes.

\section{Algumas considerações metodológicas so- bre este kit experimental: algumas possibili- dades didático-pedagógicas}

Um aspecto interessante que se pode observar em relação ao experimento abordado é que na resolução das atividades poderão ser discutidos diversos conteúdos, tais como: funções lineares, progressões geométricas, logaritmos, sistemas de equações e matrizes. Além disso, no desenvolvimento das atividades do kit analisado fica evidente que conceitos algébricos e geométricos estão interligados e podem ser utilizados de modo complementar na análise de um problema.

Destaco também que no material apresentado uma mesma situação-problema pode ser desenvolvida em níveis cada vez mais elaborados e, portanto, seguindo a abordagem do currículo em "espiral". No desenvolvimento do currículo em espiral, como proposto por Bruner (1968), as ideias básicas devem ser retomadas diversas vezes, em diferentes níveis de profundidade e modos de representação, elaborando-as e reelaborando-as até que o aprendiz adquira por completo sua formulação sistemática. Segundo Bordas (1987, p. 86), para Bruner: "[...] a recompensa de uma compreensão mais profunda é o estímulo mais poderoso [...] para levar o indivíduo a novos e mais árduos esforços."

Entretanto, vale ressaltar que é preciso tomar muito cuidado e trabalhar para que os conteúdos matemáticos envolvidos nas atividades contempladas na Experimentoteca de Matemática sejam discutidos com os alunos e, na sequência, sistematizados. A sistematização é importante porque é preciso institucionalizar o saber. Freitas (2008), com base 
principalmente no trabalho de Brousseau (1986), destaca que nas situações de institucionalização o professor procura unificar e sintetizar o conhecimento que todos os alunos produziram, visando estabelecer o caráter de objetividade e de universalidade do conhecimento.

Além disso, entende-se que atividades da Experimentoteca, como as que estão contempladas no experimento ilustrado, podem ser incorporadas em trabalhos com abordagens alternativas de ensino de Matemática, tais como a Resolução de Problemas e a Modelagem Matemática. A seguir, busca-se focalizar cada uma dessas abordagens a fim de ampliar e justificar essa compreensão.

\section{Sobre a resolução de problemas}

Schroeder e Lester Jr. (1989) analisaram diferentes trabalhos referentes ao ensino da Resolução de Problemas e destacaram três abordagens distintas, a saber: ensinar sobre Resolução de Problemas, ensinar para a Resolução de Problemas e através da Resolução de Problemas. O ensino através da Resolução de Problemas, abordagem aqui adotada, considera que a aprendizagem da Matemática deve partir de uma situação-problema para posteriormente tratar os conceitos e os procedimentos matemáticos. Nesse contexto, Onuchic (1999) considera essa abordagem como uma metodologia para o ensino de Matemática. Vale salientar que os PCN também indicam a Resolução de Problemas como ponto de partida das atividades Matemáticas. (BRASIL, 1997).

A Resolução de Problemas enquanto metodologia surge para alterar a postura do ensino tradicional, na qual os problemas são simplesmente propostos e resolvidos e sugere-se que se questionem as respostas obtidas e os próprios problemas propostos, enfatizando o processo de descoberta e não a resposta em si. (DINIZ, 1991). Nessa metodologia, o conteúdo a ser aprendido inicia-se com uma situação de aprendizagem através de um ou vários problemas-desafio significativos aos alunos; o conteúdo desconhecido aos alunos vai então sendo construído. (ONUCHIC, 1999; ONUCHIC; ALLEVATO, 2004).

Para Smole et al. (2008), a primeira característica dessa abordagem metodológica é considerar como problema toda a situação que permita uma problematização. De acordo com ONUCHIC (1999, p. 215) um problema pode ser entendido como "[...] tudo aquilo que não se sabe fazer, mas que se está interessado em resolver [...]"; ou seja, é uma situação que se apresenta como desafiadora ao aluno. Assim, Van de Walle (2001) destaca que, no contexto da Resolução de Problemas, um problema pode ser entendido como qualquer tarefa ou atividade para a qual os estudantes não possuem métodos ou regras prescritas ou memorizadas, nem a percepção de que haja um método específico para chegar à solução correta.

No ensino de Matemática através da Resolução de Problemas, o aluno assume um papel participante e ativo no processo de aprendizagem e os problemas são olhados como elementos que podem iniciar um processo de construção do conhecimento. (ONUCHIC, 1999).

Nesse sentido, compreende-se que as atividades contempladas na Experimentoteca de Matemática podem ser trabalhadas dentro da abordagem de Resolução de Problemas, uma vez que nessa Experimentoteca o conteúdo matemático é tratado a partir de um jogo, um experimento ou um conjunto de problemas, nos quais se incentiva a construção do conhecimento pelo aluno.

Quanto ao experimento focalizado neste artigo, entende-se que as atividades nele contempladas poderiam ser trabalhadas na abordagem de Resolução de Problemas, pois se propõe um conjunto de problemas em torno de uma situação principal e de seus desdobramentos. Assim, condiz com o que é posto nessa abordagem, ou seja, o conteúdo a ser aprendido inicia com uma situação de aprendizagem através de um ou vários problemas-desafio significativos aos alunos. (ONUCHIC, 1999).

Como enfatizado pelos PCN, na Resolução de Problemas, o tratamento de situações complexas e diversificadas oferece ao aluno a oportunidade de pensar por si mesmo, construir estratégias de resolução e argumentações, relacionar diferentes conhecimentos e, enfim, perseverar na busca da solução do problema em questão. (BRASIL, 1999). Por isso, a Resolução de Problemas é considerada uma abordagem apropriada para que os alunos compreendam a Matemática. (SCHOROEDER; LESTER JR., 1989).

\section{Sobre a Modelagem Matemática}

Segundo Bassanezi (2002, p. 16), a Modelagem Matemática consiste "[...] em transformar problemas da realidade em problemas matemáticos, resolvê-los e interpretar suas soluções na linguagem do mundo real". Isso é feito por meio de modelos matemáticos, os quais são compreendidos como "um conjunto de símbolos e relações Matemáticas que representam de alguma forma o objeto estudado". (BASSANEZI, 2002, p. 20). A modelagem é, portanto, uma forma de representação da realidade; um processo que alia teoria e prática e que pode ser concebido tanto como método científico de pesquisa como uma estratégia de ensino e aprendizagem. (BASSANEZI, 2002). 
No que se refere ao ensino e aprendizagem de Matemática, como salienta Silva (2006), a Modelagem Matemática constitui uma alternativa na qual se busca compreender e explicar situações idealizadas a partir da observação e problematização do mundo real e expressá-las por meio de modelos matemáticos. Em tal cenário, Barbosa (2001, p. 6) apresenta a modelagem como "[...] um ambiente de aprendizagem no qual os alunos são convidados a indagar e/ou investigar por meio da Matemática, situações oriundas de outras áreas da realidade." Salienta esse autor que tais situações podem pertencer a outras disciplinas ou fazerem parte do cotidiano.

O mesmo autor apresenta algumas possibilidades que ilustram a materialização da modelagem em sala de aula e as classificam em três níveis, nos quais à medida que se avança aumentase o grau de abertura das atividades ou situações contempladas.

O nível 1 corresponde a uma problematização de um episódio real. Nesse nível, problemas são associados a uma dada situação. As informações fornecidas no texto da situação apresentada possibilitam que o aluno a investigue.

No nível 2, o professor apresenta um problema, sendo que os dados são coletados pelos próprios alunos durante a investigação.

O nível 3 foca um tema gerador e são os alunos que formulam e solucionam os problemas.

Neste artigo, concebe-se que o experimento abordado poderia também ser compreendido dentro da abordagem de Modelagem Matemática, pois ele problematiza uma situação da realidade: a poluição do meio ambiente. O que corresponderia ao nível 1 (problematização de um episódio real) da classificação posta por Barbosa (2001), referente às possibilidades que ilustram a utilização da Modelagem Matemática em sala de aula.

Jacobini e Wodewotzki (2006) salientam que, ao explorar as aplicações Matemáticas no dia a dia, a construção de modelos e o relacionamento entre a Matemática utilizada na modelagem e o conteúdo programático, o professor oferece ao aluno a oportunidade de conviver com conteúdos vivos, práticos e significativos.

Para Almeida e Brito (2003) a atividade de Modelagem Matemática na sala de aula envolve o aluno na construção, exploração e validação de modelos matemáticos, visando o desenvolvimento de um pensamento crítico e reflexivo no estudante.

Portanto, enfatizam esses últimos autores que a exploração no ensino de situações da vida real em que se aplique a Matemática torna a aula de Matemática mais dinâmica e interessante, podendo proporcionar uma aprendizagem mais significativa.

\section{Sobre uma aplicação do experimento focado}

Uma aplicação desse experimento para alunos do Ensino Médio foi feita por uma das professoras que participou, durante o segundo ano do projeto, do grupo de discussão sobre o ensino de Matemática (Experimentoteca/CDCC) e foi apresentada como relato de experiência num congresso científico. A professora trabalhou esse material num contexto mais amplo de consciência ambiental em um trabalho interdisciplinar. De acordo com seu relato, inicialmente foi feito um levantamento de textos, relacionados às áreas de Biologia, Filosofia e Geografia, com o propósito discutir o tema meio ambiente em seu sentido mais amplo. Após a escolha de vários textos, os alunos foram divididos em grupos de, no máximo, cinco estudantes e foi distribuído a cada grupo um tema para ser discutido. Na sequência, os grupos apresentaram seus trabalhos, discutiram em conjunto com a classe, e apresentaram suas conclusões. Depois dessas atividades preliminares de leitura de textos e reflexão, os grupos passaram a trabalhar o kit experimental para o estudo da poluição do lago numa aula de Matemática. Em seu relato de experiência, a professora ainda destaca o caráter inovador do material e importância de se abordar os conteúdos matemáticos de forma significativa aos alunos.

No decorrer das aulas, pude perceber que o estudo de poluição do lago através de experimentos, além de configurar uma aula inovadora para os estudantes, trouxe a possibilidade de os alunos levantarem hipóteses e trabalharem com aproximações simplificadas, e eles obtiveram múltiplas respostas com suas respectivas justificativas. Além disso, essas aulas contribuíram de modo geral para dar mais significado aos conteúdos matemáticos vistos em sala de aula, fazendo com que os alunos compreendessem mais a fundo um conteúdo apresentado pelo professor, levando-os a pensar e refletir sobre questões que envolvem Matemática no dia a dia. (BOTTA, 2007, p. 10).

Essa professora alerta que o estudo da poluição de rios, lagos, oceanos pode ser consequência de uma interferência inadequada do homem na natureza. Daí a importância de refletirmos sobre os hábitos de consumo e de estilo de vida da população de forma geral. Ou seja, o material aborda um tema de grande importância no cenário atual.

A experiência acima reforça a percepção de que esse experimento favorece a conscientização do aluno no que se refere a problemas ambientais, busca tornar a Matemática mais concreta (o aluno manipula o material, faz suas observações e tira suas próprias conclusões) e mostra a possibilidade de utilizar a Matemática para compreensão e superação de problemas reais, compreendendo inter- 
disciplinaridade, Matemática e formação cidadã do aluno.

Isso vai ao encontro do posto por Jacobini e Wodewotzki (2006), que enfatizam a importância de se incluir no processo e ensino de aprendizagem de Matemática projetos de modelagem que visem à formação crítica e ao amadurecimento acadêmico do aluno; construídos a partir de situações-problema do cotidiano do mesmo, e que busquem aprofundar reflexões geradas pelas investigações realizadas, pelas consequências disso na sociedade e no envolvimento do estudante com a comunidade. Almeida e Dias (2004) também destacam que, por meio da Modelagem Matemática, a relação com a sociedade pode ser fortemente estimulada em sala de aula, uma vez que o problema investigado pelo aluno tem nela a sua origem.

\section{Considerações Finais}

Primeiramente, é necessário esclarecer que a Experimentoteca de Matemática está sendo compreendida neste artigo dentro de uma postura construtivista de conhecimento, segundo a qual o conhecimento é concebido como construtível e falível. Falível no sentido de não ser absoluto, estando sempre suscetível a revisões; e construtível, por ser entendido como uma elaboração do sujeito. Nessa concepção, entende-se que no ato de conhecer o aluno desempenha um papel ativo. Compreendese que, tal como já fora posto pelo grande filósofo Kant (1997), conhecer é uma função ativa do sujeito e que não podemos conhecer a não ser que nosso próprio espírito crie segundo seus níveis. Vale esclarecer que essa concepção é comum tanto à teoria de Piaget quanto à de Vygotsky, apesar desse último ter também tido a intenção de analisar as influências do contexto histórico-cultural. (FREITAG, 1991; MOYSÉS, 1997).

O construtivismo com inspiração na teoria de Piaget, denominado de construtivismo piagetiano ou radical, baseia-se nos princípios de que o conhecimento é ativamente construído pelo indivíduo cognicente (não passivamente recebido pelo meio ambiente); o ato de conhecer é um processo adaptativo que organiza um mundo experimental. Nesse sentido, não há como descobrir um mundo independente e preexistente fora da mente do conhecedor. (ERNEST, 1991, 1994). Nessa concepção de construtivismo, as aproximações do conhecimento a situações concretas ou experimentais devem se dar mediante uma ação interativa do homem com o meio ambiente e/ou com atividades (representar por imagens, comparar, manipular objetos, desenhar, usar, construir a partir do erro). (FIORENTINI, 1995). Salienta-se ainda que, nesse tipo de construtivismo, todo conhecimento é subjetivo, o que o torna limitado, pois o papel do social não é considerado.
Severino (1998) coloca que em Piaget a aprendizagem é fundamentalmente um processo de conhecimento que se dá como um processo de desenvolvimento psíquico, embora ancorado em condições estruturantes da subjetividade lógica. De acordo com esse autor, o construtivismo piagetiano não dá conta do processo educacional, porque a educação enquanto prática social, não se limita aos processos de aprendizagem. Assim, ainda segundo o autor, a teoria do psicólogo russo (Vygotsky) avança em relação ao construtivismo piagetiano, ao inserir melhor o dimensionamento lógico-formal do conhecimento no processo histórico-social em que ele se dá. Para Vygotsky, a constituição da subjetividade está necessariamente ligada à intersubjetividade.

Buscou-se elaborar as atividades da Experimentoteca de Matemática dentro da concepção de que o sujeito constrói seu conhecimento, comum à teoria de Piaget e à de Vygotsky. Entretanto, compreende-se que, tal como posto na teoria desse último, a constituição da subjetividade está necessariamente ligada à intersubjetividade. Essa intersubjetividade fez-se presente na elaboração das atividades que constituíram a Experimentoteca, visto que as trocas de experiências e ideias foram fundamentais na fase de criação das mesmas. Além disso, no que se refere às propostas das atividades a serem realizadas pelos alunos, sugere-se o desenvolvimento por meio de trabalho grupal, valorizando-se também $\mathrm{o}$ aspecto social.

Defendo, portanto, que no processo de elaboração do conhecimento, os experimentos matemáticos, tais como os desenvolvidos na Experimentoteca de Matemática, desde que trabalhados adequadamente, poderão auxiliar na criação de significados dos objetos matemáticos neles contemplados. Dentro do contexto da Aprendizagem Significativa de Ausubel, um novo conceito deve ser relacionado às estruturas de conhecimento do aluno, que adquire significado a partir da relação com seu conhecimento prévio. Caso isso não aconteça, a aprendizagem se torna mecânica ou repetitiva, o novo conteúdo passa a ser guardado isoladamente ou através de associações arbitrárias na estrutura cognitiva. Assim, quando não existe esforço consciente para relacionar o novo conhecimento, a aprendizagem será mecânica e, por consequência, esquecida mais facilmente. (NOVAK, 1981).

Moreira (1995) destaca a importância do material para a ocorrência da aprendizagem significativa, segundo esse autor, é necessário que o material a ser aprendido seja relacionável à estrutura cognitiva do aprendiz de maneira não arbitrária e não literal, sendo denominado, assim, um material potencialmente significativo.

É nesse sentido que se compreende que a criação de significados pode ser favorecida por meio 
de materiais didáticos como os da Experimentoteca. Visto que há uma preocupação de se colocar as atividades em princípio de maneira intuitiva, procurando estabelecer relações com o que o aluno sabe, e ir paulatinamente progredindo por meio de construções cada vez mais elaboradas e buscando um equilíbrio entre os aspectos intuitivo e lógico do conhecimento, como sugere a proposta de Meneghetti (2009).

Mediante a abordagem assumida, compreende-se que as atividades que compõem a Experimentoteca de Matemática possuem caráter aberto, possibilitando a incorporação de atividades complementares ou até a retomada das já existentes com outros níveis de aprofundamento. Isso pode ficar a cargo do professor levando-se em conta as peculiaridades de seus alunos, visando auxiliá-los no processo de construção do conhecimento. D'Ambrosio e Steffe (1994) salientam que caberá ao professor reformular seus conceitos e levantar novas hipóteses a serem testadas em novas situações de ensino, o que deve ser feito com base no modelo de Matemática do aluno; ou seja, é de fundamental importância considerar o contexto do aluno na aplicação de propostas para o ensino e a aprendizagem de Matemática.

O experimento focado neste artigo ilustra a sugestão de que as atividades propostas na Experimentoteca de Matemática podem ser incorporadas a abordagens alternativas de ensino de Matemática, tais como a Resolução de Problemas, Modelagem Matemática, entre outras.

Além disso, ao se conceber um Laboratório de Ensino de Matemática como "[...] um lugar da escola onde os professores estão empenhados em tornar a Matemática mais compreensível aos alunos" (LORENZATO, 2006, p. 7), a Experimentoteca mostra-se também como uma possibilidade de trabalho a ser desenvolvida nesse tipo de espaço.

Assim, nesse sentido, compreende-se que a vivência pelos alunos das atividades contempladas na Experimentoteca de Matemática, incorporadas em metodologias alternativas de ensino, podem auxiliá-los a adquirirem uma Aprendizagem Significativa dos conceitos matemáticos envolvidos. É, portanto, nesse contexto que se entende a Experimentoteca de Matemática como uma possível aliada no desenvolvimento de trabalhos alternativos em aulas de Matemática.

Agradecimentos: Aos professores e alunos que participaram do grupo de discussão sobre o ensino de Matemática, aos funcionários e ao diretor do CDCC. Ao CNPq/ VITAE/ FINEP pelo apoio financeiro no projeto da Experimentoteca do Ensino Médio do CDCC.

\section{Referências}

ALMEIDA, L. M. W; DIAS, M. R. Um estudo sobre o uso da modelagem matemática como estratégia de ensino e aprendizagem. Bolema: Boletim de Educação Matemática, Rio Claro, v. 17, n. 22, p. 19-35, 2004.

ALMEIDA, L. M.; BRITO, D. S. Modelagem Matemática na sala de aula: algumas implicações para o ensino e aprendizagem da Matemática. In: XI CONFERÊNCIA INTERAMERICANA DE EDUCAÇÃO MATEMÁTICA, 11., 2003, Blumenau. Anais... Blumenau: FURB, 2003. p. 1-11.

BARBOSA, J. C. Modelagem Matemática e os professores: a questão da formação. Bolema: Boletim de Educação Matemática, Rio Claro, v. 14, n. 15, p. 5-23, 2001.

BASSANEZI, R. C. Ensino aprendizagem como modelagem matemática: uma nova estratégia. São Paulo: Contexto, 2002.

BORDAS, M. C. Desenvolvimento cognitivo e organização de ensino na perspectiva de J. S. Bruner. In: MOREIRA, M. A.; MOSQUERA, J.; BAQUERO, R.; BORDAS, M.; BECKER, F. Aprendizagem: perspectivas teóricas. Porto Alegre: UFRGS, 1987.

BOTTA, E. S. Aplicação de atividades abordando o tema poluição de lagos numa aula de Matemática. In: ENCONTRO NACIONAL DE EDUCAÇÃO MATEMÁTICA, 9., 2007, Belo Horizonte. Anais... Belo Horizonte: UNIBH, 2007. p. 1-12.

BRASIL. Secretaria de Educação Fundamental. Parâmetros Curriculares Nacionais: Ciências Naturais. Brasília: MEC/SEF, 1997. v. 4.

. Ministério da Educação. Secretaria de Educação Média e Tecnológica. Parâmetros Curriculares Nacionais (PCN) - Ensino Médio. Brasília: MEC/SEF, 1999.

BROUSSEAU, N. Fondements et méthodes de la didactique des mathématiques. Rechercehes em Didactiques des Mathématiques, Grenoble, v. 7, n. 2, p. 33-116, 1986.

BRUNER, J. S. O processo da educação. Tradução de Lólio Lourenço de Oliveira. São Paulo: Companhia Editora Nacional, 1968.

D’AMBRÓSIO B. S.; STEFFE, L. P. O ensino construtivista. Em aberto, Brasília, v. 14, n. 62, abr./jun. 1994.

DINIZ, M. I. S. V. A metodologia "resolução de problemas". Revista do Professor de Matemática, São Paulo, v. 18, p. 12-19, 1991.

ERNEST, P. The philosophy of mathematics education. London: Falmer Press, 1991.

(Ed.). Mathematics, education and philosophy: an international perspective. London: Falmer Press, 1994.

FIORENTINI, D. Alguns modos de ver e conceber o ensino da matemática no Brasil. Revista Zetetiké, Campinas, v. 3, n. 4, p. 1-37, 1995. 
FREITAG, B. Razão teórica e razão prática: Kant e Piaget. ANDE - Revista da Associação Nacional de Educação, São Paulo, v. 15, p. 55-68, 1990.

FREITAS, J. L. M. Teoria das situações didáticas. In: MACHADO, S. D. A. (Org.). Educação Matemática: uma (nova) introdução. 3. ed. São Paulo: EDUC, 2008. p. 77-111.

GÓMEZ, A. P. O pensamento prático do professor: a formação do professor como profissional reflexivo. In: NÓVOA, A. (Org.). Os professores e a sua formação. Lisboa: Publicação Dom Quixote, Instituto de Inovação Educacional, 1992. p. 93-114.

JACOBINI, O. R.; WODEWOTZKI, M. L. L. Uma reflexão sobre a modelagem matemática no contexto da educação matemática crítica. Bolema: Boletim de Educação Matemática, Rio Claro, v. 19, n. 25, p.71-88, 2006.

KANT, I. Crítica da razão pura. Tradução de Manuela Pinto dos Santos e Alexandre Fradique Mourujão. 4. ed. Lisboa: Fundação Caloute Gulbenkian, 1997.

LOCKE, J. An essay concerning human understanding. Chicago: Encyclopedia Britannica 'Great Books', 1980.

LORENZATO, S. (Org.). O laboratório de ensino de matemática na formação de professores. Campinas: Autores Associados, 2006. (Coleção Formação de Professores).

MENEGHETTI, R. C. G. O Intuitivo e o lógico no conhecimento matemático: análise de uma proposta pedagógica em relação a abordagens filosóficas atuais e ao contexto educacional da matemática. Bolema: Boletim de Educação Matemática, Rio Claro, v. 22, n. 32, p. 161-188, 2009.

MENEGHETTI, R. C. G.; BICUDO, I. Uma discussão sobre a constituição do saber matemático e seus reflexos na educação matemática. Bolema: Boletim de Educação Matemática, Rio Claro, v. 16, n. 19, p. 58-72, 2003.

MOREIRA, M. A. A teoria de Ausubel. In: Ensino e aprendizagem: enfoques teóricos. São Paulo: Moraes, 1995. p. 61-73.

MOURA, M. O. A séria busca no jogo: do lúdico na matemática. Educação Matemática em Revista, São Paulo, v. 2, n. 3, p. 17-24, 1994.

MOYSÉS, L. Aplicações de Vygotsky à educação matemática. Campinas: Papirus, 1997.

NOVAK, J. D. Uma teoria de educação. Tradução de Marco Antonio Moreira. São Paulo: Pioneira, 1981.

OLIVEIRA, H.; PONTE, J. P. Investigação sobre concepções, saberes e desenvolvimento profissional dos professores de matemática. In: Associação de Professores de Matemática. Actas do SIEM VII. Lisboa: Associação de Professores de Matemática, 1997. p. 3-23. Disponível em: <http://www.educ.fc.ul.pt/docentes/ jponte/artigos-por-temas.htm>. Acesso em: 19 maio 2011.
ONUCHIC, L. R. Ensino-aprendizagem de matemática através de resolução de problemas. In: BICUDO, M. A. V. (Org.). Pesquisa em educação matemática: concepções e perspectivas. São Paulo: UNESP, 1999. p. 199-218.

ONUCHIC, L. R.; ALLEVATO, N. S. G. Novas reflexões sobre o ensino-aprendizagem de matemática através da resolução de problemas. In: BICUDO, M. A. V.; BORBA, M. C. (Org.). Educação matemática: pesquisa em movimento. São Paulo: UNESP, 2004. p. 213-231.

PASSOS, C. L. B. Materiais manipuláveis como recursos didáticos na formação de professores de matemática. In: LORENZATO, S. (Org.). O laboratório de ensino de matemática na formação de professores. Campinas: Autores Associados, 2006. p. 77-92.

SALVADOR, J. A. et al. Projeto integrado de ciências e matemática para professores da rede pública de São Carlos e região. In: ENCONTRO DE EXTENSÃO DA UFSCAR, 4., 2003, São Carlos. Anais... São Carlos: UFSCAR, 2003. p. 228

SANDEFUR, J. T. Drugs and pollution in the algebra class. The Mathematics Theaching, v. 85, n. 2, p. 139145, Feb. 1992.

SCHROEDER. T. L.; LESTER JR., F. K. Developing understanding in mathematics via problem solving. In: TRAFTON, P. R.; SHULTE, A. P. (Ed.). New directions for elementary school mathematics. Reston: National Council of Teachers of Mathematics, 1989. p. 31-42.

SEVERINO, A. J. Produção de conhecimento, ensino/ aprendizagem e educação. Interface - Comunicação, Saúde, Educação, Botucatu, v. 2, n. 3, p. 11-20, ago. 1998. DOI: 10.1590/S1414-32831998000200002

SILVA, M. D. S. F. da. O uso da modelagem matemática num curso de Matemática Aplicada para alunos de Economia e Administração. Educação Matemática em Revista, São Paulo, v. 13, n. 20-21, p. 64-68, dez. 2006.

SMOLE, K. C. S. et al. Cadernos do Mathema: jogos de matemática de $1^{\circ}$ a $3^{\circ}$ ano. Porto Alegre: Artmed, 2008.

TOMAZELLO, M. G. C.; SCHIEL, D. O livro da experimentoteca: educação para as ciências da natureza através de práticas experimentais. Piracicaba: Gráfica Alves VITAE/UNIMEP/USP, 1998. v. 1.

VAN DE WALLE, J. A. teaching through problem solving. In: Elementary and middle school mathematics. New York: Longman, 2001.

Recebido em 09/03/2010

Versão final recebida em 25/06/2010

Aceito em 29/04/2011 